\title{
Regulated Expression of the Cell Adhesion Glycoprotein F3 in Adult Hypothalamic Magnocellular Neurons
}

\author{
Karin Pierre, ${ }^{1}$ Geneviève Rougon, ${ }^{2}$ Michèle Allard, ${ }^{1}$ Renée Bonhomme, ${ }^{1}$ Gianfranco Gennarini, ${ }^{3}$ \\ Dominique A. Poulain, ${ }^{1}$ and Dionysia. T. Theodosis ${ }^{1}$ \\ 1/nstitut National de la Santé et de la Recherche Médicale U378 Neurobiologie Morphofonctionelle, Institut François \\ Magendie, F33077 Bordeaux Cedex, France, ${ }^{2}$ Centre National de la Recherche Scientifique UMR 9943 Laboratoire de \\ Génétique et Physiologie du Développement, Parc Scientifique de Luminy, F13288 Marseille Cedex 9, France, and \\ ${ }^{3}$ Dipartimento di Farmacologia e Fisiologia Umana, University of Bari, Bari, I 702124 Italy
}

F3, a glycoprotein of the immunoglobulin superfamily implicated in axonal growth, occurs in oxytocin (OT)-secreting and vasopressin (AVP)-secreting neurons of the adult hypothalamoneurohypophysial system (HNS) whose axons undergo morphological changes in response to stimulation. Immunocytochemistry and immunoblot analysis showed that during basal conditions of HNS secretion, there are higher levels of this glycosylphosphatidyl inositol-anchored protein in the neurohypophysis, where their axons terminate, than in the hypothalamic nuclei containing their somata. Physiological stimulation (lactation, osmotic challenge) reversed this pattern and resulted in upregulation of F3 expression, paralleling that of OT and AVP under these conditions. In situ hybridization revealed that F3 expression in the hypothalamus is restricted to its magnocellular neurons and demonstrated a more than threefold increase in F3 mRNA levels in response to stimulation. Confocal and electron microscopy localized F3 in secretory granules in all neuronal compartments, a localization confirmed by detection of F3 immunoreactivity in granule-enriched fractions obtained by sucrose density gradient fractionation of rat neurohypophyses. F3 was not visible on any cell surface in the magnocellular nuclei. In contrast, in the neurohypophysis, it was present not only in secretory granules but also on the surface of axon terminals and glia and in extracellular spaces.

Taken together, our observations reveal that the cell adhesion glycoprotein F3 is colocalized with neurohypophysial peptides in secretory granules. It follows, therefore, the regulated pathway of secretion in HNS neurons to be released by exocytosis at their axon terminals in the neurohypophysis, where it may intervene in activity-dependent structural axonal plasticity.

Key words: hypothalamo-neurohypophysial system; cell adhesion molecules; plasticity; lactation; dehydration; in situ hybridization; immunocytochemistry; immunoblot analysis
Oxytocin (OT) and vasopressin (AVP), the neuropeptides secreted by magnocellular neurons of the hypothalamoneurohypophysial system (HNS), intervene in several neuroendocrine functions, including lactation and osmotic regulation. Under these physiological conditions of stimulation, the conformation of the neurons, their afferent inputs, and the glial cells surrounding them become reorganized, a form of structural neuronal plasticity that includes enlargement and ramification of their axonal terminals in the neurohypophysis where the neuropeptides are released (for review, see Theodosis and Poulain, 1993; Hatton, 1997). In a search for factors involved in such plasticity, we have found that the HNS continues to display, in the adult, several molecular features associated with neurohistogenesis, including expression of cell adhesion molecules such as F3

\footnotetext{
Received April 8, 1998; accepted April 30, 1998.

Part of this work was supported by grants from the Conseil Général d'Aquitaine to D.T.T. and l'Association Française contre la Myopathie to G.R. We are grateful to Professor B. Bloch and his colleagues for their generous support and guidance in performing the in situ hybridization histochemistry. Special thanks are also due to Dr. J. M. Israel for his help in carrying out some of the experiments; Drs. D. Aunis, H. Gainer, V. Geenen, M. H. Metz-Boutigue, A. Robinson for their gifts of antibodies; Dr. C. Henderson for his critical reading of this manuscript; C. Reis for technical assistance; and S. Senon and I. Svahn for their photographic expertise.

Correspondence should be addressed to D. T. Theodosis, Institut National de la Santé et de la Recherche Médicale U378 Neurobiologie Morphofonctionelle, Institut François Magendie, 1 Rue Camille Saint-Saëns, F33077 Bordeaux Cedex, France.

Copyright (C) 1998 Society for Neuroscience $\quad 0270-6474 / 98 / 185333-11 \$ 05.00 / 0$
}

(Theodosis et al., 1991, 1994, 1997; Bonfanti et al., 1992; Olive et al., 1995b).

F3, a glycoprotein with an apparent molecular weight of 135 $\mathrm{kD}$, is a member of the $\mathrm{Ig}$ superfamily preferentially associated with axons (Gennarini et al., 1989). Earlier observations (FaivreSarrailh et al., 1992; Yoshihara et al., 1995) indicated that F3 is expressed by subgroups of developing neurons, and its distribution is consistent with a presumed role in the control of axonal growth and synaptogenesis. F3 is composed of Ig- and fibronectin-like domains that provide a framework for different recognition sites and functions. It is bound to membranes by covalent attachment to a glycosylphosphatidyl inositol (GPI) anchor, which means that it can exist in membrane-bound or soluble form and can act as neuronal receptor and substratum ligand. F3 appears to modulate neurite outgrowth via heterophilic interactions of its Ig-like domains with distinct cell surface or extracellular matrix components, which in turn may mediate either adhesive or repellent effects (for review, see Faivre-Sarrailh and Rougon, 1997).

Our earlier studies described F3 immunoreactivity in adult HNS neurons. They suggested that such expression was circumscribed to the HNS, because under axonal transport block by colchicine only magnocellular somata displayed high levels of F3 in the hypothalamus (Olive et al., 1995b). In this report, we demonstrate by in situ hybridization, by immunoblot analysis, and by light, confocal, and electron microscopic immunocytochemis- 
try that F3 expression in this part of the brain is indeed restricted to HNS neurons. In addition, we show that its expression is activity-dependent and follows closely the different patterns of OT and AVP secretion occurring under various physiological conditions that stimulate these neurons and induce structural plasticity. Last, we give morphological and biochemical evidence demonstrating that F3 is colocalized with OT or AVP in secretory granules, thus providing a mechanism by which this particular cell adhesion molecule is targeted, via a regulated pathway of secretion, to adult nerve terminals capable of structural plasticity.

\section{MATERIALS AND METHODS}

\section{Animals}

Male and female Wistar rats $(250-400 \mathrm{gm})$ raised under controlled temperature and light conditions were used. They were divided into four groups: (1) normally hydrated male and virgin female rats, 3 months of age, that were given food and water ad libitum; (2) male and female dehydrated rats, at least 3 months of age, that had been given dry food but had been deprived of water for $24 \mathrm{hr}$; (3) salt-loaded male and female rats, whose drinking water had been replaced with $2 \% \mathrm{NaCl}$ for $10 \mathrm{~d}$; and (4) lactating females that had nursed a litter of 10 pups for at least $3 \mathrm{~d}$ and were provided with food and water ad libitum.

\section{In situ hybridization histochemistry}

For radiolabeling of probes, F3 cDNA was cloned in a $\mathrm{pGEM} 7 \mathrm{z}$ vector ( $3 \mathrm{~kb}$; Promega, Madison, WI). The probe was prepared by digesting the plasmid-F3 cDNA with restriction enzymes HindIII and XHO I (1 hr, $37^{\circ} \mathrm{C}$ ), which yielded $0.7 \mathrm{~kb} \mathrm{5} 5^{\prime}-3^{\prime} \mathrm{cDNA}$. Insert fragments were purified by precipitation overnight in $100 \%$ ethanol at $-20^{\circ} \mathrm{C}$ and centrifugation for $20 \mathrm{~min}$ at $13,000 \times \mathrm{g}$; pellets were resuspended in $25 \mu \mathrm{l}$ Tris-EDTA (6\% Tris, $1 \%$ EDTA, $\mathrm{pH} 8.2$ ) and frozen. The probe was labeled by in vitro transcription $\left(1.5 \mathrm{hr}\right.$ at $\left.37^{\circ} \mathrm{C}\right)$ with ${ }^{35} \mathrm{~S}-\mathrm{UTP}(1000 \mathrm{Ci} / \mathrm{mmol}$; New England Nuclear) using RNA polymerases (T7 polymerase for the antisense transcript or sp6 polymerase for the sense transcript; Boehringer Mannheim, Mannheim, Germany). After alkaline hydrolysis (32 min, $60^{\circ} \mathrm{C}$ ) to obtain $200 \mathrm{bp}$ fragments, radio probes were separated from unincorporated nucleotide on a G-50 Sephadex column. After precipitation (overnight, in absolute ethanol at $\left.-20^{\circ} \mathrm{C}\right)$ and centrif ugation $(1 \mathrm{hr}$ at $13,000 \times g)$, pellets were resuspended in $24 \mu \mathrm{l}$ Tris-EDTA-DTT $(6 \%$, $1 \%, 50 \mathrm{~mm}$, respectively) and frozen.

Hybridization was performed according to a procedure described in detail in Le Moine and Bloch (1995). Reactions were performed on sections obtained from four normally hydrated, two dehydrated, five salt-loaded, and three lactating rats that under urethane anesthesia (1.5 $\mathrm{gm} / \mathrm{kg}$, i.p.) had been perfused with a freshly prepared solution of $1 \%$ paraformaldehyde in sodium phosphate buffer (0.1 M, pH 7.4). After dissection, brains were left in $20 \%$ saccharose in phosphate buffer for 48 $\mathrm{hr}$ and frozen in isopentane at $-60^{\circ} \mathrm{C}$. Serial frontal or sagittal sections $(10 \mu \mathrm{m})$ were cut on a cryostat, thaw-mounted on gelatin-covered slides, and kept at $-20^{\circ} \mathrm{C}$. In each experiment, sections that included equivalent areas of the hypothalamus from each group were treated concurrently. Before hybridization, the sections were post-fixed with $4 \%$ paraformaldehyde ( $5 \mathrm{~min}$, room temperature), rinsed in sodium citrate buffer (SSC;

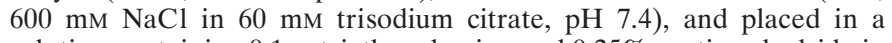
solution containing $0.1 \mathrm{~m}$ triethanolamine and $0,25 \%$ acetic anhydride in SSC. After dehydration in an ascending series of ethanol and drying at room temperature, the sections were hybridized with the ${ }^{35} \mathrm{~S}$-labeled probe $\left(1-210^{6} \mathrm{cpm} / \mathrm{slide}\right)$ in yeast tRNA $(250 \mu \mathrm{g} / \mathrm{ml})$ and salmon sperm DNA $(100 \mu \mathrm{g} / \mathrm{ml})$, all dissolved in hybridization buffer (50\% formamide, $300 \mathrm{~mm} \mathrm{NaCl}, 20 \mathrm{~mm}$ Tris-HCl at pH 7.4, 1 mm EDTA, and Denhardt's solution). After rinsing in SSC containing $1 \mathrm{~mm}$ DTT, they were incubated in an RNase solution $(20 \mu \mathrm{g} / \mathrm{ml})$ at $37^{\circ} \mathrm{C}$, followed by another rinse in SSC and DTT in a humidified chamber at $65^{\circ} \mathrm{C}$. They were then dehydrated in ethanol, coated with x-ray film (Biomax, Kodak), and left in $\mathrm{x}$-ray cassettes at $4^{\circ} \mathrm{C}$ for $8 \mathrm{~d}$. Films were developed in Kodak D19. The sections were dipped in liquid Ilford K5 emulsion, developed for 3-4 weeks at $4^{\circ} \mathrm{C}$, and counterstained with toluidine blue. Specificity of labeling was controlled by treating adjacent sections with sense-labeled probe or with labeled probe diluted in hybridization buffer; no specific signal was visible in such sections.

Estimation of F3 mRNA labeling was performed by determining silver grain density (number of silver grains per micrometer squared) over neuronal somata, using an image analyzer (Histo 200, Biocom, Les Ulis, France) and a procedure described in detail in Le Moine and Bloch (1995). Counts were obtained from the supraoptic nucleus (SON) in its middle portion in the frontal plane. At least two sections from two different SONs per animal were analyzed, from at least two animals per group.

\section{Immunocytochemistry}

Tissues were obtained from 15 normally hydrated, 13 dehydrated, 11 salt-loaded, and 9 lactating rats. Under urethane anesthesia, the rats were injected intracardially with heparin and then perfused with a solution of $4 \%$ paraformaldehyde, $0.15 \%$ picric acid, and $0.1 \%$ glutaraldehyde in phosphate buffer $(0.1 \mathrm{M}, \mathrm{pH} 7.4 ; 300 \mathrm{ml}$ during $20 \mathrm{~min})$. Hypophyses and blocks containing the hypothalamus were removed from each brain and post-fixed in $4 \%$ paraformaldehyde overnight at $4^{\circ} \mathrm{C}$. Blocks of hypothalamus and hypophysis were then cut on a vibratome to obtain frontal slices $(50-75 \mu \mathrm{m})$, which were collected in buffer or infiltrated with $20 \%$ saccharose for $48 \mathrm{hr}$, frozen in isopentane at $-60^{\circ} \mathrm{C}$, and cut with a cryostat to obtain frontal sections $(25 \mu \mathrm{m})$, which were collected in phosphate buffer. Additionally, small blocks $\left(1 \mathrm{~mm}^{3}\right)$ of hypothalamic tissue that included the SON were infiltrated with $2.3 \mathrm{M}$ sucrose in phosphate buffer, mounted on specimen stubs, and frozen in liquid nitrogen; semithin sections $(700 \mathrm{~nm})$ were cut at $-85^{\circ} \mathrm{C}$ on an Ultracut ultramicrotome (Reichert-Leica, Vienna, Austria) fitted with a cryosectioning unit; they were collected on poly-L-lysine-coated slides.

Light microscopy. For single immunostaining, standard immunofluorescence and immunoperoxidase techniques were performed on freely floating vibratome $(50-75 \mu \mathrm{m})$ or frozen $(25 \mu \mathrm{m})$ sections, according to procedures described in detail in Olive et al. (1995b). Briefly, all sections were treated with casein ( $0.5 \%$ in PBS) for 1 hr to block nonspecific sites and then incubated in rabbit antisera raised against either the whole F3 molecule [for production and specificity see Gennarini et al. (1989)] or a fusion protein comprising the Ig-like domains of F3 (Gennarini et al., 1989); they were used at a dilution of 1:800 for immunoperoxidase reactions and 1:400 for immunofluorescence $\left(24-48 \mathrm{hr}\right.$ at $\left.4^{\circ} \mathrm{C}\right)$. Affinitypurified fluorescein isothiocyanate (FITC)-conjugated goat anti-rabbit Ig (diluted 1:400; Biosys) or sheep anti-rabbit Ig (1:200, Biosys), followed by the rabbit peroxidase-antiperoxidase (PAP) complexes, (1:500; Dakopatts, Copenhagen, Denmark) were used as immunolabels. Peroxidase reaction product was revealed with either 3,3'-diaminobenzidine (DAB, $0.1 \%$ ) and $0.01 \% \mathrm{H}_{2} \mathrm{O}_{2}$ or with glucose oxidase-nickel-DAB (Shu et al., 1988). The sections were examined with a Leica DMR microscope, using bright- and dark-field optics for the peroxidase-containing sections and epifluorescence with appropriate filters for the fluorochrome-treated sections. Controls included omitting the primary serum or its substitution by nonimmune rabbit serum. No specific staining was visible on such preparations.

For double-immunostaining, freely floating sections were first incubated for $1 \mathrm{hr}$ in casein $(0.5 \%$ in PBS) and then in mixtures of primary antibodies containing anti-F3 serum (diluted 1:500) and mouse monoclonal $\mathrm{IgG}$ raised against either oxytocin-related neurophysin (Np-OT, diluted 1:400) (Ben-Barak et al., 1985) or AVP [diluted 1:10,000 (characterized in Moll et al., 1988); $48 \mathrm{hr}$ at $4^{\circ} \mathrm{C}$. After careful rinsing in Tris-buffered saline (TBS), the sections were incubated in mixtures of different fluorescent conjugates $(2 \mathrm{hr}$, room temperature). Goat FITCconjugated anti-rabbit Ig (diluted 1:400) was used to identify F3 immunoreactivity, whereas goat anti-mouse Ig conjugated with Texas Red (1:400, Biosys) or 7-amino-4-methyl-coumarin-3-acetic-acid (AMCA; 1:200, Biosys) was used to visualize neuropeptide immunoreactivities. The sections were examined with epifluorescence with appropriate filters.

Confocal microscopy. Confocal microscopy was used to examine serial, semithin $(700 \mathrm{~nm})$ frozen sections of the SON, which had undergone double immunofluorescence for F3 and either of the neuropeptides. The immunolabeling was as described above, except that all antibody solutions were applied as drops on the sections; the incubations were performed in a humidified chamber. Ten serial optical sections were collected $(0.1 \mu \mathrm{m} / \mathrm{step}$; pixel size, $0.11 \mathrm{~mm})$ on a confocal microscope (Inverted CLSM System, Molecular Dynamics, Sunnyvale, CA). Each section was examined individually or was used to generate projections for either F3 (green, visualized with FITC-conjugated Ig) or Np-OT (red, visualized with Texas Red-conjugated Ig). The two projections were merged to give simultaneous visualization of the two antigens.

Electron microscopy. Blocks containing the SON, paraventricular nucleus (PVN), or neurohypophysis were dissected from vibratome slices 
that underwent immunoperoxidase labeling for F3. They were osmicated in $1 \% \mathrm{OsO}_{4}$ in phosphate buffer, dehydrated with increasing concentrations of ethanol, and embedded in Epon resin. To enhance contrast, the tissues were block-stained with $1.5 \%$ uranyl acetate in $50 \%$ ethanol during dehydration. After identification in semithin sections, ultrathin sections were cut from selected areas and mounted on nickel grids. They were examined without any further contrast with a Philips CM10 electron microscope.

\section{Immunoblot analysis}

On tissue extracts. The tissues were obtained from 18 male rats that underwent no treatment, 12 dehydrated (water-deprived) rats, and 15 lactating rats. All animals were decapitated under urethane anesthesia, and the brain and hypophyses were removed rapidly. The SON was then dissected under microscopic control from frontal slices $(400-500 \mu \mathrm{m}) \mathrm{cut}$ on a vibratome, and the neurohypophyses were freed from adjacent hypophysial lobes. After dissection, all tissues were quickly frozen on dry ice and pooled in Eppendorf tubes to yield samples representing tissue from three different animals under the same experimental condition. After thawing, the tubes were quickly centrifuged to pellet the tissues, which were then homogenized with an adapted conical Teflon pestle in $50 \mu \mathrm{l}$ of $50 \mathrm{~mm}$ Tris buffer, pH 7.4, containing $0.25 \mathrm{M}$ sucrose, $10 \mathrm{~mm}$ HEPES, $5 \mathrm{mM}$ EDTA, the protease inhibitors phenyl methyl sulfonyl fluoride, $\alpha$-2-macroglobulin, and leupeptin at appropriate concentrations (Boehringer Mannheim, Meylan, France), and 2\% sodium deoxycholate. Tubes were left for $30 \mathrm{~min}$ at $4^{\circ} \mathrm{C}$ with frequent shaking to allow protein solubilization and then centrifuged at $30,000 \mathrm{rpm}$ for $15 \mathrm{~min}$ in an OptimaTL-100 ultracentrifuge using a 100.3 rotor equipped with adaptors (Beckman). Supernatants, containing sodium deoxycholate soluble proteins, were recovered and protein concentration was determined using a Bradford assay. Extracts were mixed with sample buffer containing $5 \mu \mathrm{M}$ dithiothreitol and boiled for $3 \mathrm{~min}$; they were resolved by $7 \%$ SDS-PAGE. After electrophoresis, the proteins were transferred to Hybond $\mathrm{C}$ nitrocellulose (Amersham, Les Ulis, France) for $2 \mathrm{hr}$ at $0.6 \mathrm{~A}$. After saturation in $5 \%$ defatted milk in PBS $\left(2 \mathrm{hr}, 37^{\circ} \mathrm{C}\right)$, they were incubated for $12 \mathrm{hr}$ at $4^{\circ} \mathrm{C}$ with an anti-F3 antiserum directed against the Ig domains of F3 [1:1000; for production and characterization, see Olive et al. (1995b)]. The membranes were incubated for $2 \mathrm{hr}$ at $20^{\circ} \mathrm{C}$ with HRP-conjugated goat anti-rabbit Ig (1:10 000), and bound antibodies were revealed by chemiluminescence (ECL Kit, Boehringer Mannheim). All parameters of the procedure were kept standardized to compare data obtained in independent experiments. Bands on films were scanned using a BioImage scanner (Microteck) and quantified using MacBAS V2.2 software (Fuji Photofilm and Koshin Graphic Systems).

To test the reproducibility of the immunoblot technique, tissues from six additional dehydrated rats were pooled. The protein extracts were divided into two samples and immunoblotted as above, independently; F3 levels obtained for these two samples were similar (data not shown).

On granule-enriched subcellular fractions. For this, rat neurohypophyses (six per experiment) were quickly dissected and pooled in eppendorf tubes. They were then gently homogenized by hand using a conical Teflon pestle in $500 \mu \mathrm{l}$ medium containing $300 \mathrm{~mm}$ sucrose, $4 \mathrm{~mm}$ HEPES, pH 7.2, $5 \mathrm{~mm}$ EDTA, and the protease inhibitors described above. The homogenate was centrifuged at $100 \times g$ for $10 \mathrm{~min}$. The resulting supernatant was loaded on a $0.3-2.0 \mathrm{M}$ sucrose gradient and spun for $5 \mathrm{hr}$ in a rotor (JA 25.50, Beckman J-25) at $65,000 \times g$, as described previously (Navone et al., 1989). After centrifugation, aliquots of the gradient were collected, acidified $\left(0.1 \mathrm{~N}^{-\mathrm{HClO}_{4}}\right)$, and centrif uged at $10,000 \times g$. For neurophysin and secretogranin II visualization, the supernatants were discarded, and pellets were redissolved in $100 \mu \mathrm{l}$ of 50 $\mathrm{mM}$ Tris-HCl, pH 7.4, containing $150 \mathrm{mM} \mathrm{NaCl}$ and protease inhibitors; for F3, the solubilization solution contained $2 \%$ sodium deoxycholate. Tubes were then left for $2 \mathrm{hr}$ (at $4^{\circ} \mathrm{C}$ ), with frequent shaking to allow protein solubilization, and centrifuged at $10,000 \times g$ for $15 \mathrm{~min}$. Supernatants were recovered, dried, and redissolved in sample buffer containing $5 \mu \mathrm{M}$ dithiothreitol; they were then boiled for $3 \mathrm{~min}$. Forty milliliters of each sample were separated on 7 or $10 \%$ SDS-PAGE for F3 or neurophysin and secretogranin II, respectively. They were then transferred to nitrocellulose, as described above. After saturation of nonspecific sites with $5 \%$ nonfat dry milk in TBS, the blots were incubated overnight in rabbit sera raised against F3 (see above) or in neurophysin [diluted 1:2000; described in Roberts et al. (1991)] or in secretogranin II [diluted 1:1000; raised against a-secretoneurin or CGC165-182 (M. H. Metz-Boutigue and D. Aunis, personal communication)]. Bound antibodies were revealed using alkaline phosphatase-conjugated secondary
Ig and a Life Technologies-BRL kit (Boehringer Mannheim), and blots were scanned as described above.

\section{RESULTS}

\section{F3 expression in HNS neurons}

As shown in Figure 1, F3 mRNA was detectable in sections of the hypothalamus by in situ hybridization with ${ }^{35} \mathrm{~S}$-labeled probes. The transcripts were restricted to the magnocellular nuclei, but their levels varied markedly in relation to the condition of the animals. In normally hydrated, nongestating rats undergoing low levels of HNS secretion, there was no specific labeling in the PVN, and in the SON it was detected only over a few neuronal somata (Fig. 1a). In contrast, high levels of F3 mRNA were visible, to a similar extent, throughout the SON, PVN, and accessory magnocellular groups in lactating rats (Fig. $1 b$ ) and in rats that underwent osmotic challenge, either by water deprivation or substitution of their drinking water with saline (Fig. 1c). Estimation of silver grain densities over individual SON somata showed that there was a significant threefold increase in the group of salt-loaded rats, in comparison with the normally hydrated group $\left(0.37 \pm 0.16\right.$ grains $/ \mu \mathrm{m}^{2}, n=119$ cells, vs $0.10 \pm 0.09$ grains $/ \mu \mathrm{m}^{2}, n=134$ cells; three animals per group; $p<0.05$, Mann-Whitney $U$ test). A similar increase in grain densities was detected in SON neurons in the dehydrated and lactating groups $\left(0.35 \pm 0.19\right.$ grains $/ \mu \mathrm{m}^{2}, n=57$ cells, and $0.64 \pm 0.28$ grains/ $\mu \mathrm{m}^{2}, n=98$ cells, respectively; two animals per group).

As visualized with immunocytochemistry, levels of F3 protein varied in a similar manner in the SON and PVN of the different groups of animals. In accord with our earlier study (Olive et al., 1995b), we detected a variable amount of F3 immunoreactivity in comparatively few magnocellular somata and fibers in the nuclei of unstimulated rats (Fig. 2a), whereas strong F3 labeling characterized most magnocellular somata and fibers in the hypothalamus of animals in which HNS secretion was stimulated, by either lactation or osmotic challenge (Fig. $2 b$; see Fig. $5 a, b$ ). On the other hand, in comparison with unstimulated animals (Fig. 3a), there was a consistent reduction in F3 immunoreactivity in the neurohypophysis of stimulated rats, particularly after osmotic stimulation (Fig. 3b). These variations in F3 immunolabeling in the different portions of the HNS paralleled those characteristic of immunolabeling for OT or AVP performed on the same (see Fig. $5 a, b)$ or adjacent sections. The internal layer of the median eminence, through which neurohypophysial axons transit, appeared heavily labeled for F3 (Fig. 3c), as for the neuropeptides, in all animals, regardless of their condition.

Immunoblot analysis confirmed the presence of F3 immunoreactivity, migrating as a band of $135 \mathrm{kD}$, in extracts of the rat SON and neurohypophysis (Fig. 4). The quantity of F3 varied considerably, in relation to the tissue and to the condition of the animals. As in our earlier study (Olive et al., 1995b), we found that levels of F3 in unstimulated rats were significantly higher in the neurohypophysis than in the SON. On the other hand, our present analyses demonstrated that stimulation of neurohypophysial secretion evoked a dramatic increase in F3 levels in the SON, accompanied by a large decrease in the neurohypophysis, especially in response to osmotic stimulation.

\section{F3 is colocalized with neurohypophysial peptides}

Double-immunofluorescent labeling of frozen sections for F3 and either of the neurohypophysial peptides made it obvious that F3 immunoreactivity occurred in both OT-secreting and AVPsecreting neurons, regardless of the physiological condition of the 

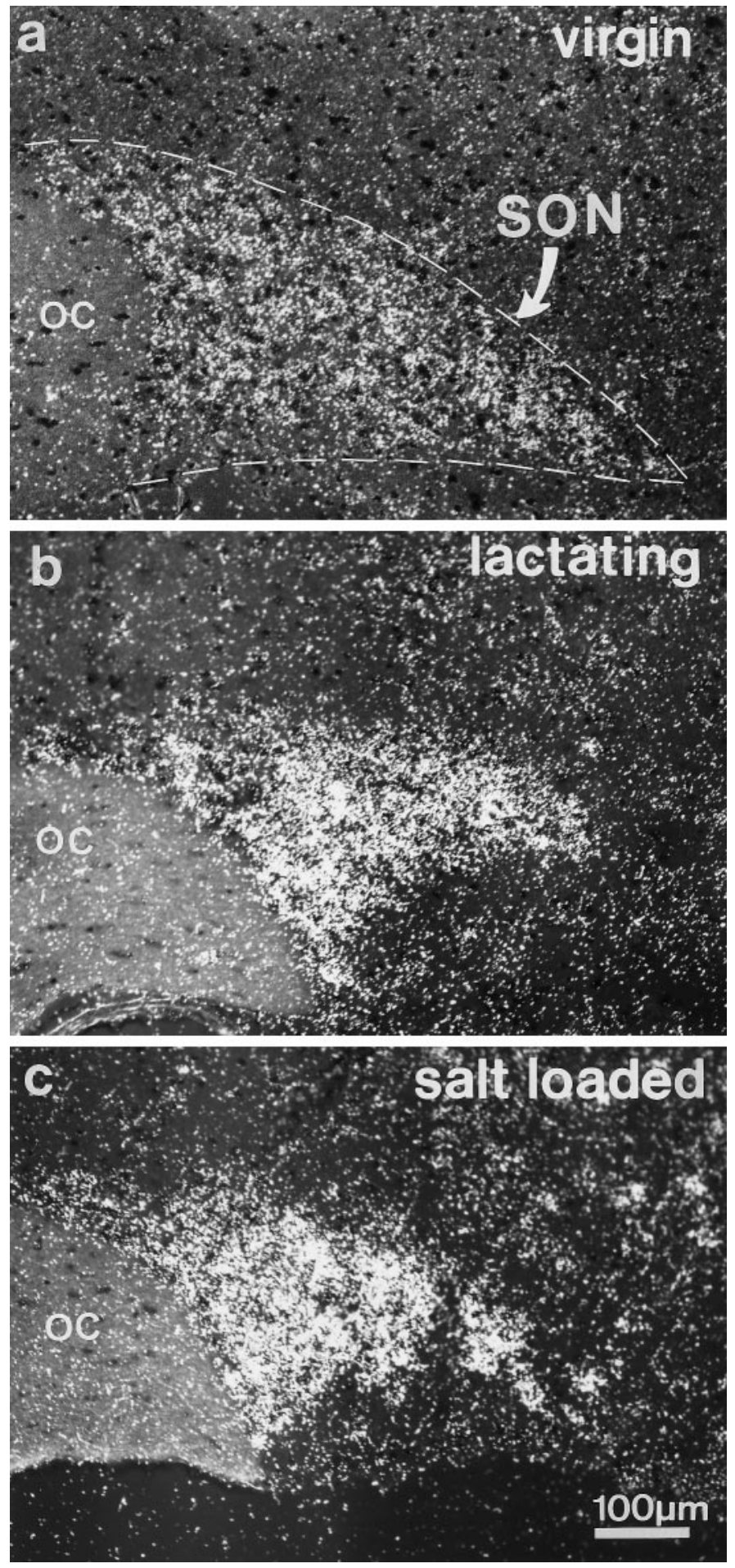

Figure 1. In situ hybridization detection of ${ }^{35} \mathrm{~S}$-labeled F3 mRNA in the adult rat hypothalamus. F3 transcripts are visible, restricted to the supraoptic nucleus $(S O N)$. Under basal conditions of HNS secretion (normally hydrated virgin rats), only a small hybridization signal is detectable $(a)$. In contrast, in lactating $(b)$ and osmotically challenged (salt-loaded) (c) rats, high levels of F3 transcripts are visible throughout the nucleus. Autoradiography was performed on frozen $(10 \mu \mathrm{m})$ frontal sections. $O C$, Optic chiasma. animal (Fig. 5). Semithin (700 nm) frozen sections afforded better resolution of the reaction (Fig. $5 c$ ) and showed without ambiguity that F3 labeling in the magnocellular nuclei was restricted to neuronal somata and fibers. The staining was intracytoplasmic, and no reaction was visible on cell surfaces. In these sections, the reaction appeared punctate, with a distribution pattern similar to that obtained after labeling the same sections for either of the neurohypophysial peptides (Fig. 5c1). Confocal analysis demonstrated clear overlap of F3 and peptide immunoreactivities over the same punctae (Fig. 5c2).

Electron microscopy of immunoperoxidase-labeled ultrathin sections allowed us to determine that the punctate F3 labeling seen on light and confocal microscopic images was caused by the accumulation of $\mathrm{F} 3$ reaction over dense-cored secretory granules in the cytoplasm of neuronal somata and fibers in the SON and PVN (Fig. 6a,b). F3 labeling of secretory granules was also visible in neurosecretory terminals in the neurohypophysis (Fig. 6c).

Using confocal and electron microscopy, we saw no reaction for F3 on any cellular surface in the magnocellular nuclei. In contrast, electron microscopy of the neurohypophysis clearly showed F3 immunoreactivity on the surface of neurosecretory terminals and glia (pituicytes) and in extracellular spaces (Fig. 6c). The association of F3 immunoreactivity with axonal terminal surfaces was highlighted by its presence in profiles at various stages of endocytosis, ranging from simple, reaction-filled invaginations of the cell surface (Fig. 6d,e) to intracellular multivesicular bodies of variable complexity and size (Fig. 6f,g). Additionally, F3-labeled endocytotic invaginations were at times detected on glial (pituicyte) surfaces (Fig. 6c). In agreement with our light microscopic observations, F3 labeling was generally diminished in the neurohypophyses from stimulated animals, but the cellular and subcellular distribution of the reaction was similar to that visible in unstimulated animals.

Finally, the presence of F3 immunoreactivity in neurosecretory granules was confirmed by immunoblot analysis of sucrose density gradients of rat neurohypophyses. In these preparations, F3 immunoreactivity was detected in fractions enriched with secretory granules $(1.2-1.8 \mathrm{M})$, as evidenced by reaction of the same fractions for other granule proteins, such as neurophysin and secretogranin II (Fig. 7).

\section{DISCUSSION}

Three principal findings emerge from our observations. First, expression of the Ig-related cell adhesion molecule F3 in the hypothalamus is restricted to its magnocellular peptidergic neurons. Second, such expression is closely correlated with neuronal activity. Third, in addition to its expected localization on axonal surfaces, this GPI-anchored glycoprotein is present in secretory granules that package and transport peptides from somata to axon terminals for release by exocytosis. In adult HNS neurons, then, F3 secretion follows a regulated pathway closely linked to that controlling secretion of neurohypophysial peptides. This implies that the different patterns of electrical activity characteristic of OT and AVP neurons during lactation and osmotic regulation dictate not only the particular patterns of synthesis and release of these peptides (for review, see Poulain and Wakerley, 1982) but those of an adhesion molecule as well. In response to these stimuli, neurohypophysial axons undergo morphological changes similar to those implicating F3 during development (Theodosis and Poulain, 1993; Hatton, 1997), which strongly suggests that F3 participates in activity-dependent structural axonal plasticity in the adult as well. 

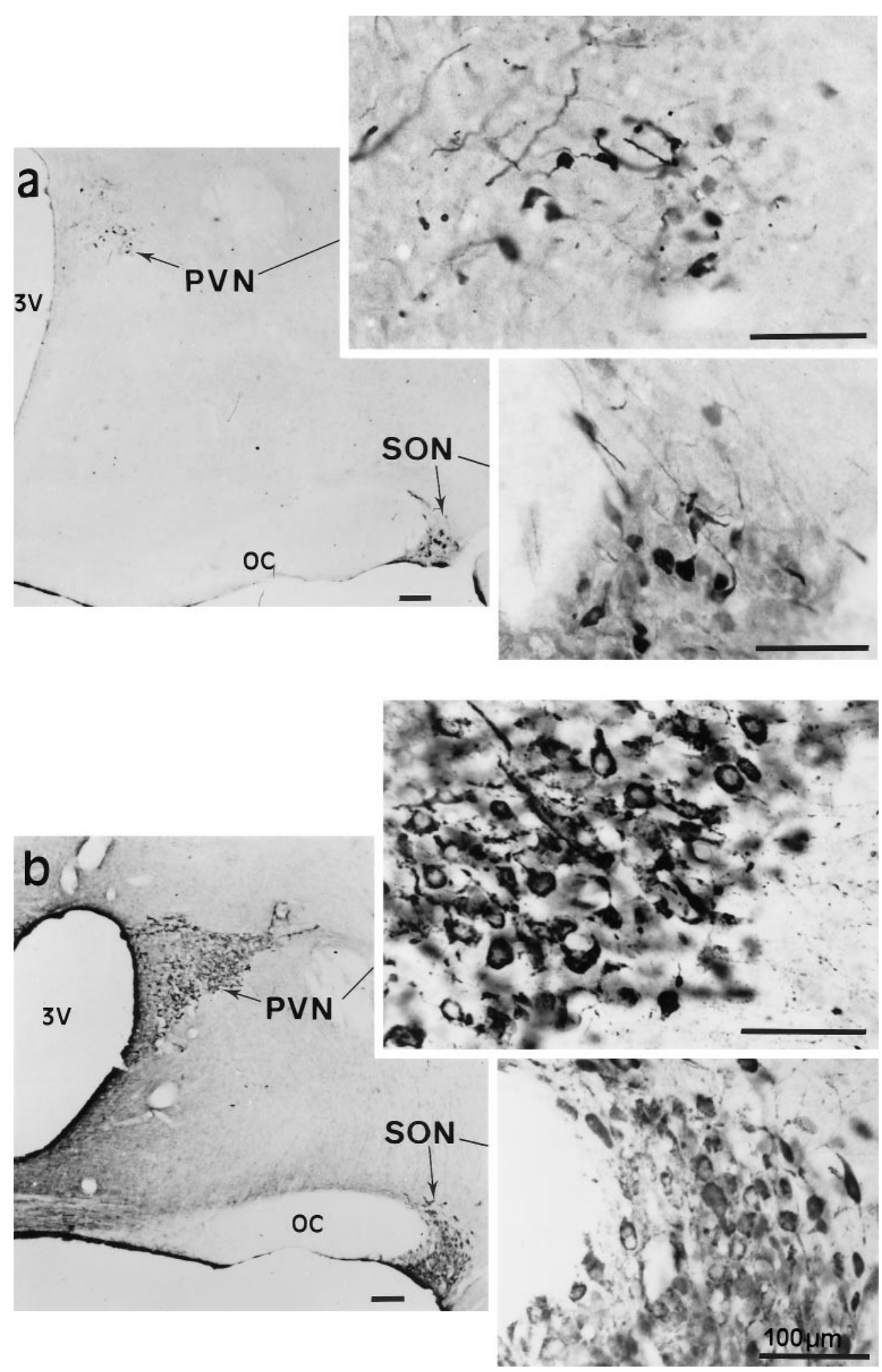

Figure 2. Immunolocalization of F3 glycoprotein in the adult rat hypothalamus. $a$, In virgin rats, under basal conditions of secretion, F3 immunoreactivity is seen in a few magnocellular somata and dendrites in the $S O N$ and $P V N$ (shown also at higher magnification in the insets). $b$, In dehydrated rats, strong F3 labeling characterizes most magnocellular neurons in the SON and PVN. Higher magnification (insets) shows that the reaction fills neuronal somata as well as dendritic and axonal processes. Note the absence of specific labeling in the adjacent hypothalamus. Immunoperoxidase labeling of frontal vibratome sections $(50 \mu \mathrm{m})$ revealed with glucose oxidase-nickelDAB; bright-field optics. $O C$, Optic chiasma; $3 V$, third ventricle.

\section{Neuronal activity influences F3 expression}

F3 expression was studied under conditions known to increase significantly the electrical, biosynthetic, and secretory activities of HNS neurons (for review, see Gainer and Wray, 1994). One of the most striking observations of this study was how closely the pattern of F3 expression paralleled that of the neurohypophysial peptides.

High levels of F3 mRNA transcripts and protein were detected in magnocellular somata of rats under acute (water deprivation) and prolonged (salt-loading) osmotic challenge. These stimuli increase OT and AVP gene and peptide expression (Brownstein et al., 1980; Gainer and Wray, 1994) and result in hypertrophy of the neurons (Hatton, 1997). Neuronal electrical activity is greatly enhanced (for review, see Poulain and Wakerley, 1982), which then promotes exocytosis of secretory granules from all neurosecretory terminals (Brownstein et al., 1980). This leads to a grad- 


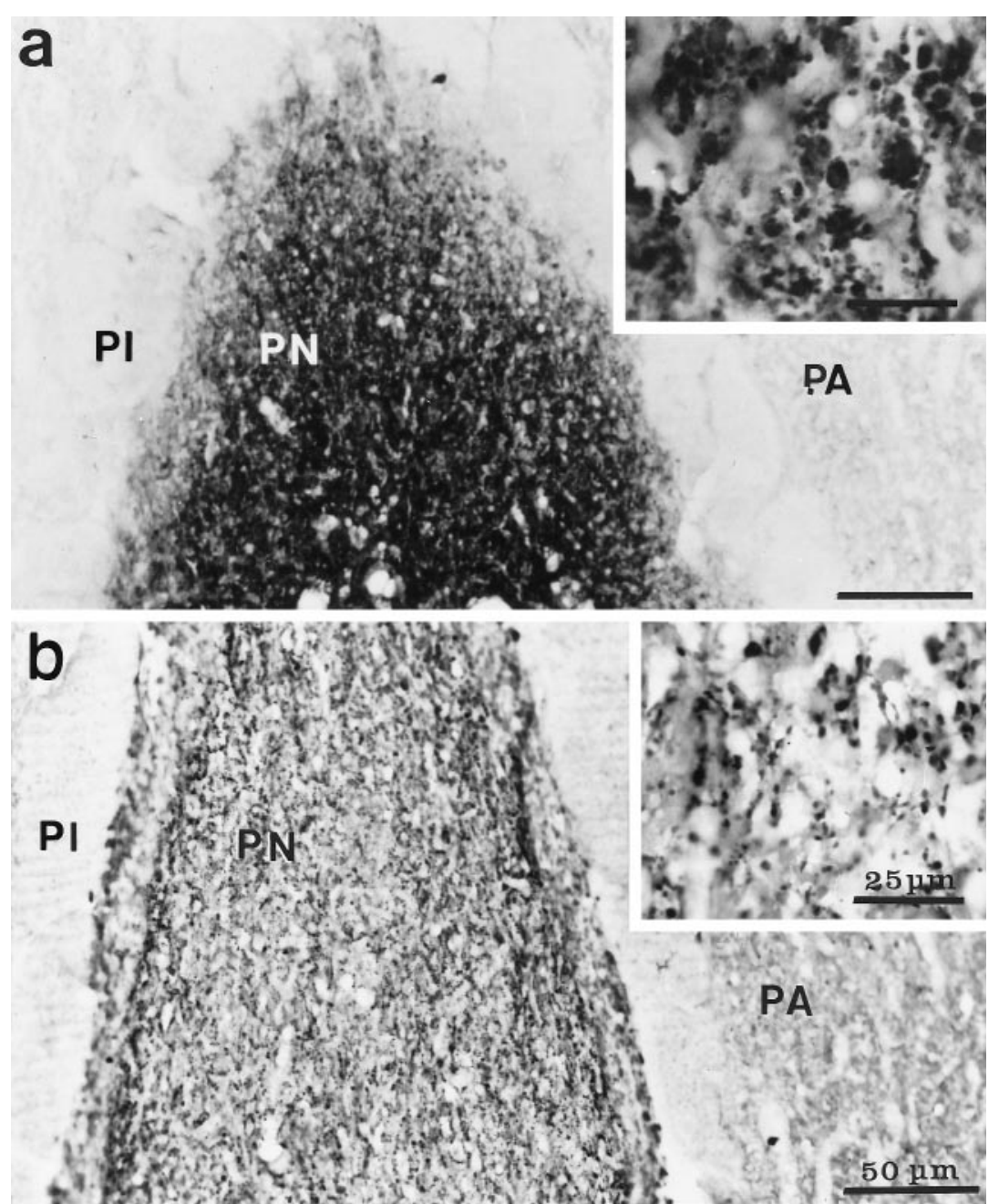

Figure 3. F3 immunoreactivity in the hypophysis of normal $(a)$ and dehydrated $(b)$ adult rats. Labeling is restricted to the posterior lobe $(P N)$, or neurohypophysis, where it appears associated with fibers and dilatations (shown at higher magnification in the insets). The reaction is greatly diminished in glands of stimulated rats $(b)$. Immunoperoxidase labeling was revealed with $\mathrm{DAB}$ and viewed with bright-field optics. $P A$, Pars anterior; $P I$, pars intermedia. $c, \mathrm{~F} 3$ immunoreactivity in the median eminence (me) of a dehydrated rat. Immunoperoxidase labeling (here illustrated with dark-field optics) revealed a strong signal, regardless of the condition of the animal, throughout its internal layer, where the HNS tract courses.

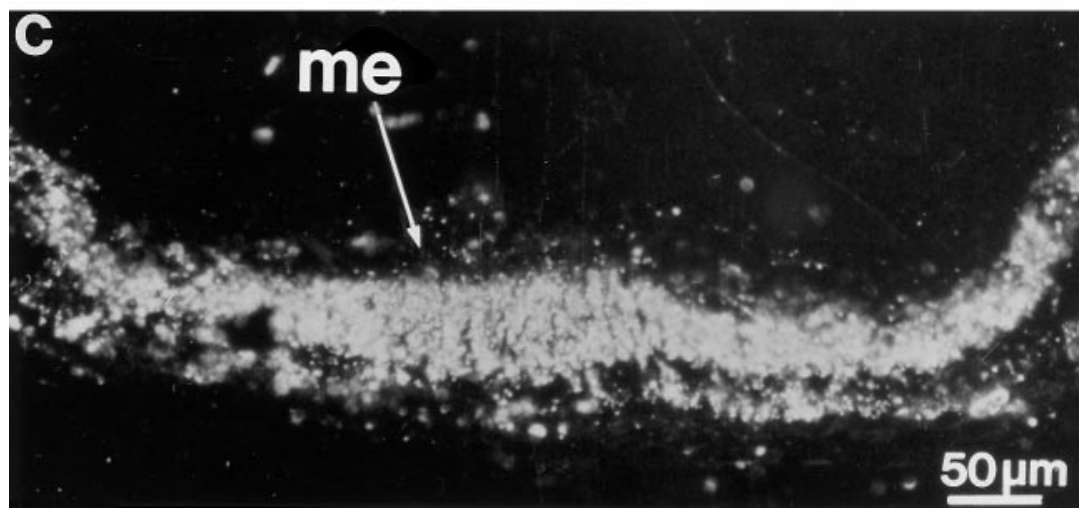

ual depletion of the large stores of peptides in the neurohypophysis, despite increased synthesis in the hypothalamus (for review, see Gainer and Wray, 1994). As shown here, the same stimuli induced parallel changes in F3 expression, resulting in upregulation of F3 levels in the hypothalamic nuclei and reduction in the neurohypophysis. Suckling raises OT mRNA and peptide levels in the hypothalamic nuclei and induces significant neuronal hypertrophy (El Majdoubi et al., 1997). Neurohypophysial stores of the peptides are also diminished but to a lesser extent than that induced by the osmotic stimuli (Gainer and Wray, 1994). The levels of F3 mRNA and protein in the different portions of the HNS in lactating animals followed a closely similar pattern.
Our observations thus contribute to increasing evidence linking neuronal activity and expression of cell adhesion molecules. Nevertheless, variable effects have been reported, depending on the adhesion molecule and the neuronal system under study. For example, although electrical pulses delivered to cultured sensory neurons downregulated expression of L1 mRNA and protein, they did not affect neural cell adhesion molecule (NCAM) expression (Itoh et al., 1995). In Aplysia, stimulation by serotonin downregulated surface expression of Aplysia CAM (Bailey et al., 1992), but in developing cortical (Kiss et al., 1994) and hippocampal (Muller et al., 1996) neurons, electrical activity induced surface expression of the highly sialylated isoform of polysialylated 

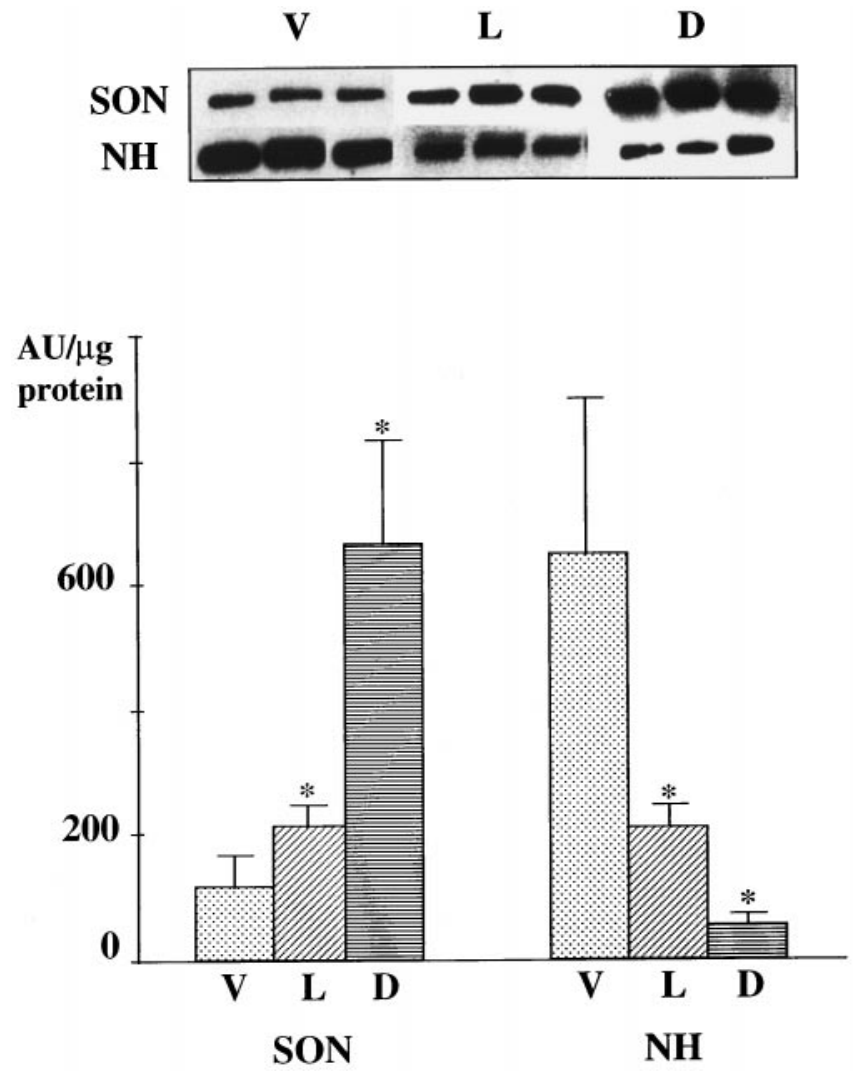

Figure 4. Immunoblot analysis of F3 in the supraoptic nucleus (SON) and neurohypophysis $(\mathrm{NH})$ of rats under basal and stimulated conditions of neurohormone release. Immunoreactivities were revealed with peroxidase-conjugated antibodies and chemiluminescence. F3 appeared as a $135 \mathrm{kD}$ band in all tissue extracts (top). In unstimulated virgin rats $(V)$, there is significantly more F3 in the NH than in the SON. Stimulation, either by lactation $(L)$ or water deprivation $(D)$, was accompanied by significant increases in levels of F3 in the SON and significant decreases in the NH. The data were obtained from three different samples of extracts, each representing tissues from three animals under the same experimental conditions per sample. ${ }^{*}$ indicates significantly different from the corresponding values in virgin rats at $p<0.05$, Mann-Whitney $U$ test. $A U$, Arbitrary units.

NCAM (PSA-NCAM). As we have seen here, activation of the HNS clearly upregulated F3 mRNA and protein expression.

Adult HNS neurons and glia express other adhesion molecules associated with neurohistogenesis, such as PSA-NCAM (Theodosis et al., 1991; Bonfanti et al., 1992; Kiss et al., 1993), L1 (Grant et al., 1992), and tenascin-C (Theodosis et al., 1994, 1997; Singleton and Salm, 1996). In comparison with F3, however, their expression shows little variation on stimulation. If anything, levels of PSA-NCAM (Nothias et al., 1997) and tenascin-C (Singleton and Salm, 1996) immunoreactivities seem to decrease in the SON of stimulated rats; concurrently, they appear unmodified in the neurohypophysis (Theodosis et al., 1991, 1997). This means then that mechanisms regulating their biosynthesis and metabolism differ from those regulating biosynthesis and secretion of F3 and the neurohypophysial peptides.

\section{Colocalization of F3 with neurohypophysial peptides}

The patterns of expression of F3 in the HNS become comprehensible when we take into account the cellular and subcellular localization of the molecule. From our observations, it was clear that F3 mRNA and protein were limited to the magnocellular neurons and were absent from all other cells in the hypothalamus and hypophysis.

F3 immunoreactivity was consistently visible in the cytoplasm of the neurons in all parts of the HNS and was detected on surfaces of neurosecretory axon terminals only in the neurohypophysis. It is noteworthy that an axonal localization of F3 also characterizes F3 expression in cerebellar granule cells (FaivreSarrailh et al., 1992), as it does other GPI-anchored adhesion molecules in other neurons (Dotti et al., 1991; Lierheimer et al., 1997).

In addition, our biochemical and morphological observations demonstrate that in HNS neurons, F3 is present in neurosecretory granules. We were thus able to detect F3 immunoreactivity in granule-enriched sucrose density fractions from rat neurohypophyses, fractions identified by reaction to other secretory granule markers such as neurophysin or secretogranin II (WalchSolimena et al., 1993). With electron microscopy, F3 immunoreactivity was visualized directly in neurosecretory granules in all portions of these neurons. Such a localization then explains the granular aspect of F3 immunolabeling obtained with light and confocal microscopy and its overlap with the granular neuropeptide immunoreaction.

The presence of F3 in secretory granules means then that this particular adhesion molecule follows the regulated pathway of secretion (for review, see Burgess and Kelly, 1987) and is released by exocytosis in response to electrical signals controlling the release of neurohypophysial hormones. This would explain why F3 levels diminished in the neurohypophysis in response to stimuli known to empty neurosecretory axons of their granules by exocytosis. Moreover, the presence of F3 in secretory granules connotes a particular sorting and packaging of the molecule in the Golgi, for which its GPI anchor may be responsible (also see Brown and Rose, 1992). What the present observations do not tell us, however, is whether F3 is part of the granule membrane or granule core or both. Our earlier immunoblot analysis detected soluble and GPI-bearing forms in the neurohypophysis (Olive et al., 1995b), and as seen here it is localized on the surface of neurosecretory terminals, in their endocytotic profiles and in extracellular spaces. If F3 is part of the granule membrane, it may be incorporated into the axonal surface on fusion of the two membranes during exocytosis; it could then be released specifically by an endogenous GPI-cleavage enzyme, as happens for axonin-1, another GPI-linked molecule (Lierheimer et al., 1997). Alternatively, F3 may be present in soluble form already in the granule core and may be released as such into the extracellular space; its presence on axonal surfaces then implies reaction with specific receptors.

Although F3 can be detected in the neurohypophysis even after prolonged sustained stimuli, its levels are markedly reduced under chronic stimuli, as are those of the neurohypophysial peptides. It is likely, therefore, that like the peptides, some F3 passes through the fenestrated capillaries of the gland and escapes into the bloodstream. Another possibility is degradation of secreted F3, although we did not detect degradative products with our immunoblot methods (data not shown). Secreted F3 may also become fixed to glial (pituicyte) surfaces and then internalized by endocytosis and rapidly degraded in lysosomes. Certainly, pituicytes undergo active endocytosis, whose rate is closely linked to secretion in adjacent axons (Theodosis, 1979). Although pituicytes do not synthesize F3 (F3 mRNA was never detected in these or other HNS glial cells), F3 was visible on pituicyte surfaces and in endocytotic invaginations (Fig. 6). One likely glial 

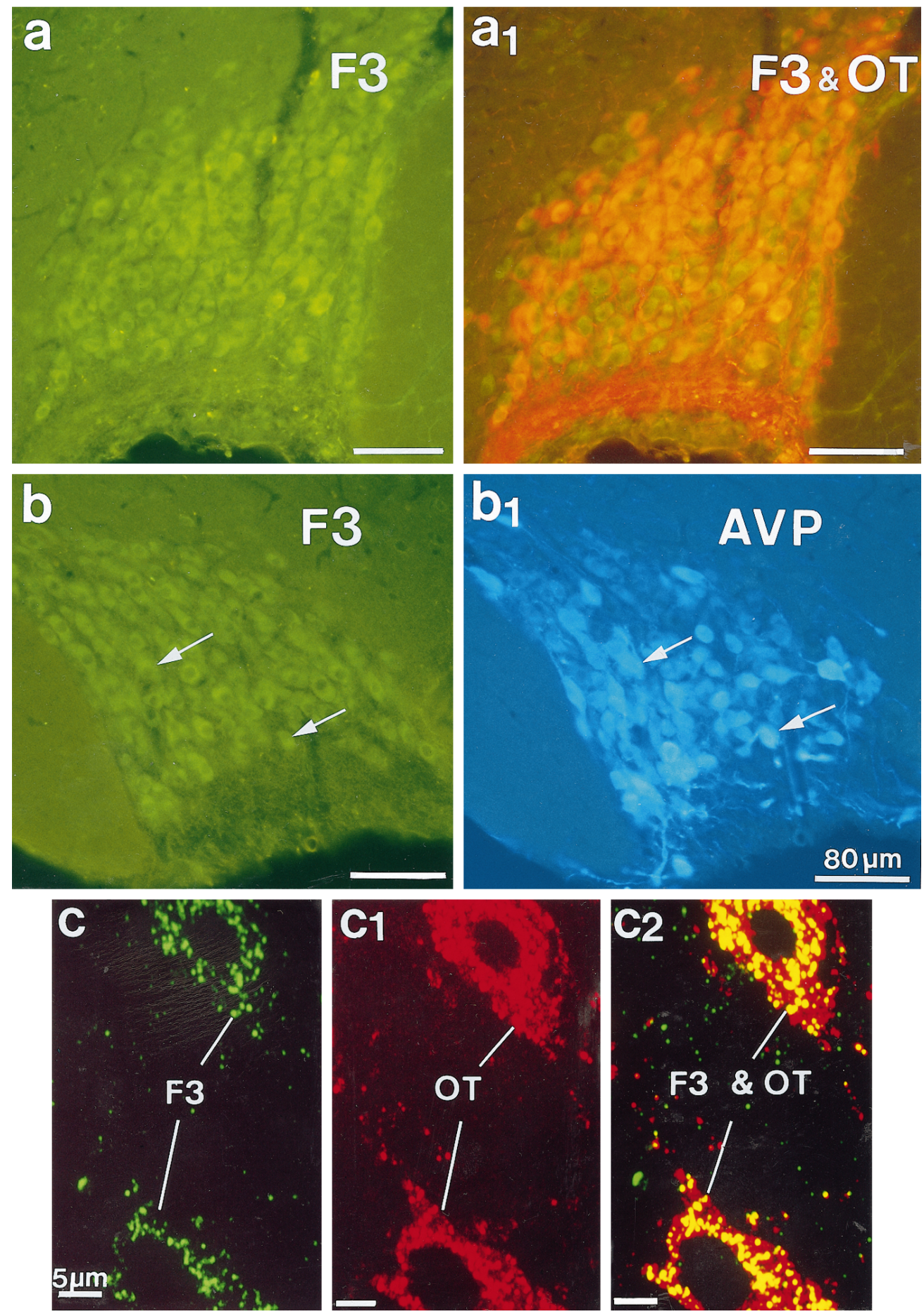

Figure 5. Simultaneous immunofluorescent localization of F3 and oxytocin $(O T)$ or vasopressin $(A V P)$ immunoreactivities in the SON. F3 was visualized with FITC-conjugated (green) antibodies; OT and AVP were visualized with Texas Red and AMCA-conjugated (blue) antibodies, respectively. $a, b$, Light microscopy of frozen frontal sections $(25 \mu \mathrm{m})$ showed F3 immunoreactivity ( green, $a, b)$ in magnocellular somata and fibers throughout the nucleus, colocalized with OT (orange, a1) or AVP (arrows, $b$ and b1). Epifluorescence with appropriate filters was used. $c$, $c 2$, Confocal microscopy of a semithin $(700 \mathrm{~nm}$ ) frozen section of the SON simultaneously immunolabeled for F3 ( green, $c$ ) and OT (red, $c 1)$. In $c$ and $c 1$, each image represents a single optical projection. Note that the labeling for F3, as for OT, is punctate and is dispersed throughout the cytoplasm of somatic and dendritic profiles. In $c 2$, the red-green overlay of the two antigens clearly shows colocalization ( yellow) of the two immunoreactivities over the same punctae. Note that immunolabeling caused by OT is more extensive than that caused by F3. The better resolution afforded by these sections shows clearly that labeling for F3, as for the neuropeptide, is intracytoplasmic; no reaction is visible on either somatic or dendritic surfaces. 

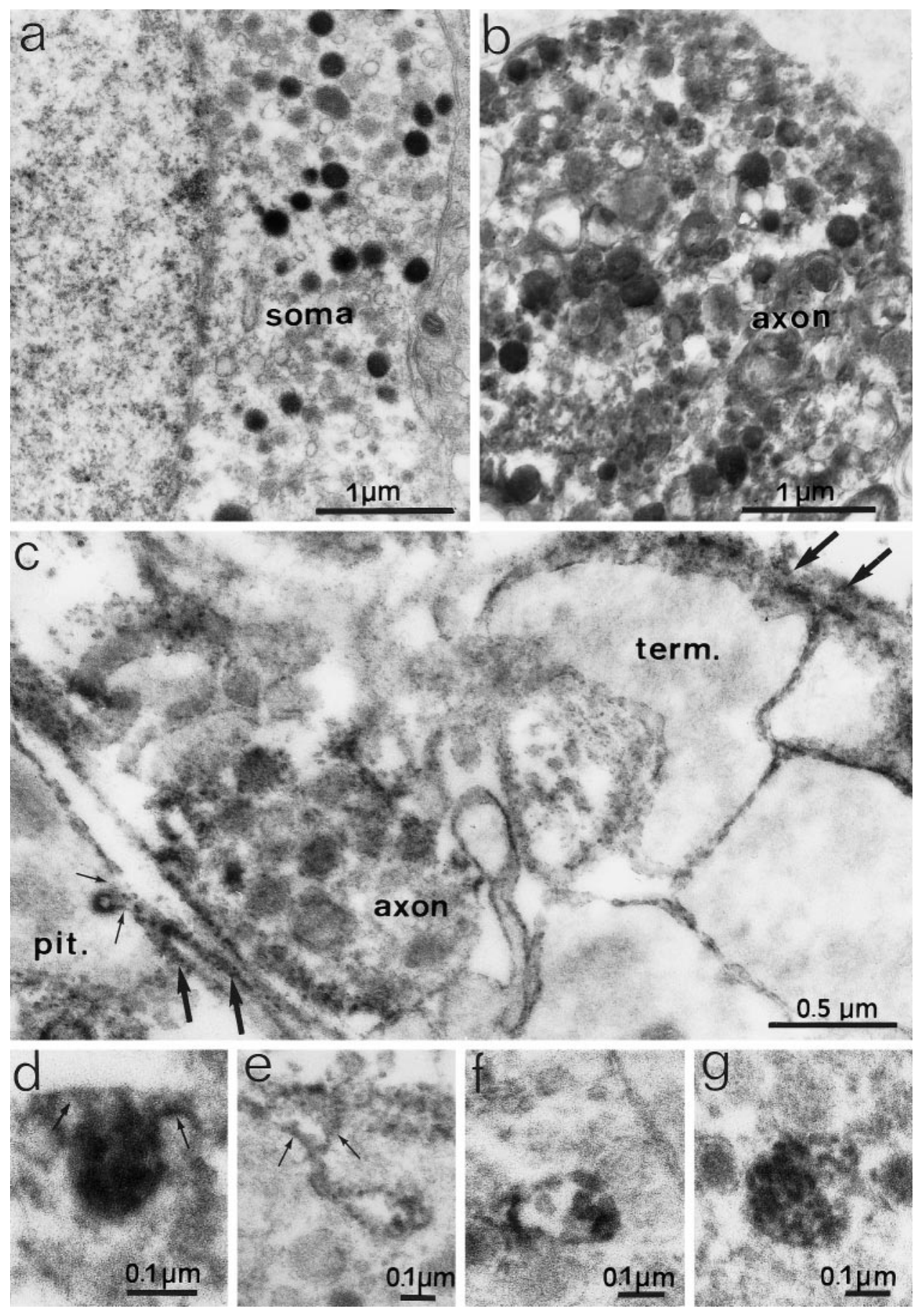

erm.

receptor candidate for such interactions is tenascin- $\mathrm{C}$, which is known to interact with F3 (Zisch et al., 1992) and to be present in large amounts on pituicyte surfaces (Theodosis et al., 1997).

\section{F3 and structural axonal plasticity}

During neurohistogenesis, F3 is thought to intervene in intercellular adhesion and in neurite outgrowth (for review, see FaivreSarrailh and Rougon, 1997). Moreover, various in vitro models (Gennarini et al., 1991; Durbec et al., 1992; Brümmendorf et al., 1993) indicate that F3 actively modulates axonal growth. In the stimulated HNS, neurohypophysial axons ramify and enlarge, thus increasing the neurohemal contact area; these morphological changes are reversible with cessation of stimulation (for review,
Figure 6. Electron micrographs depicting F3 immunoreactivity in noncounterstained ultrathin sections of the SON (a, $b)$ and neurohypophysis $(c-g)$ of adult rats after preembedding immunoperoxidase staining. Electron-dense peroxidase reaction product representing F3 immunoreactivity covers secretory granules in the cytoplasm of somatic $(a)$ and axonal $(b, c)$ profiles. Labeling of neuronal surfaces is absent in the $\operatorname{SON}(a, b)$ but is present on the surfaces of axon terminals (term.) and glial cells in the neurohypophysis $(c-e)$. Note that the reaction product is associated with invaginations (arrows) of glial $(c)$ and terminal $(d, e)$ surfaces and with multivesicular bodies $(f, g)$ in axon terminals. In the neurohypophysis $(c)$, reaction also occurs in extracellular spaces (large arrows).

see Theodosis and Poulain, 1993; Hatton, 1997). Because changes in F3 expression accompany these morphological changes, it is possible that $\mathrm{F} 3$ participates in axonal remodeling, not only during development but in the adult as well. How this occurs remains to be determined, but it is possible that modifications in F3 release in response to HNS stimulation modulate the ratios of soluble to anchored forms of F3 and thus modify adhesive interactions between neurohypophysial axons and their surroundings.

Nevertheless, F3 cannot be the sole factor responsible for the complex interactions underlying the morphological changes in the adult neurohypophysis. However, its reported properties make it an excellent candidate at least for its participation. As seen in vitro, F3 function depends on heterophilic interactions with dif- 


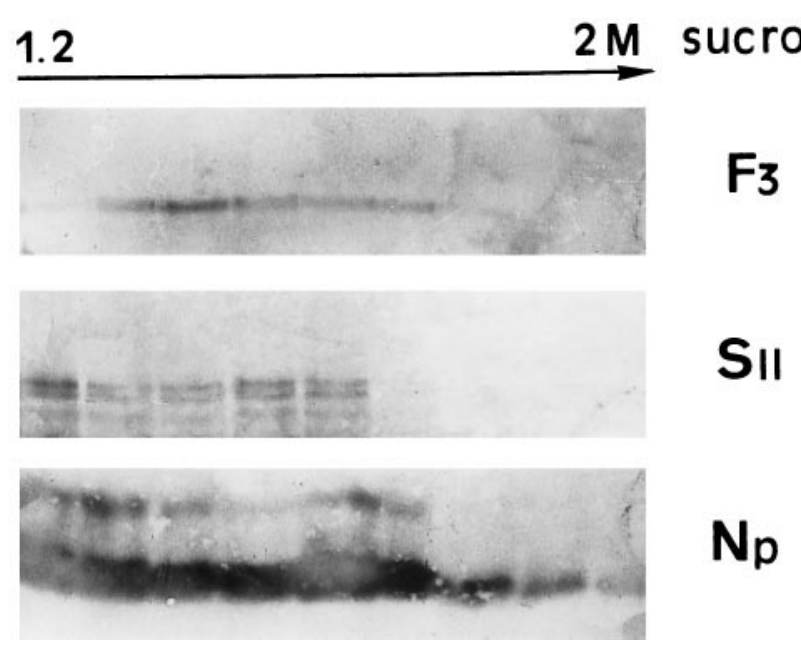

Figure 7. Distribution of F3 and the secretory granule proteins secretogranin II $\left(S_{I I}\right)$ and neurophysin $(\mathrm{Np})$ after sucrose density gradient fractionation of adult rat neurohypophyses. After SDS-PAGE and immunoblotting, immunoreactivities for each protein are visible in fractions collected from the bottom of the gradient. Protein immunoreactivities were detected with alkaline phosphatase-conjugated secondary antibodies.

ferent cell surface or matrix glycoproteins, acting either as receptors or ligands (Faivre-Sarrailh and Rougon, 1997). These molecules include extracellular matrix tenascins (Zisch et al., 1992; Pesheva et al., 1994), axonal receptors such as L1 (Olive et al., 1995a), or glial receptors such as tyrosine phosphatase $\beta$ (Peles et al., 1995; Sakurai et al., 1997). The interactions are complex and result in adhesive and repellent effects. As noted earlier, some of these molecules, such as tenascin-C (Theodosis et al., 1997) and L1 (Grant et al., 1992), occur in large amounts in the neurohypophysis. Because their expressions do not vary markedly with stimulation, it may be that it is the changing levels of F3 that modify the balance of ligand/receptor interactions, thereby acting as a signal to initiate new adhesive or repulsive interactions between the axons and their glial and matrix environments.

\section{REFERENCES}

Bailey CH, Chen M, Keller F, Kandel ER (1992) Serotonin-mediated endocytosis of apCAM: an early step of learning-related synaptic growth in Aplysia. Science 256:645-649.

Ben-Barak Y, Russell JT, Whitnall MH, Ozato K, Gainer H (1985) Neurophysin in the hypothalamo-neurohypophysial system: I. Production and characterization of monoclonal antibodies. J Neurosci 5:81-97.

Bonfanti L, Olive S, Poulain DA, Theodosis DT (1992) Mapping of the distribution of polysialylated neural cell adhesion molecule throughout the central nervous system of the adult rat: an immunohistochemical study. Neuroscience 49:419-436.

Brown D, Rose K (1992) Sorting of GPI-anchored proteins to glycolipidenriched membrane subdomains during transport to the apical cell surface. Cell 68:533-544.

Brownstein MJ, Russell JT, Gainer H (1980) Synthesis, transport, and release of posterior pituitary hormones. Science 207:373-378.

Brümmendorf T, Hubert $\mathrm{M}$, Treubert $\mathrm{U}$, Leuschner R, Tarnok A, Rathjen FG (1993) The axonal recognition molecule F11 is a multifunctional protein: specific domains mediate interactions with $\mathrm{Ng}$ CAM and restrictin. Neuron 10:711-727.

Burgess TL, Kelly RB (1987) Constitutive and regulated secretion of proteins. Annu Rev Cell Biol 3:243-293.

Dotti CG, Parton RG, Simons K (1991) Polarized sorting of glypiated proteins in hippocampal neurons. Nature 349:158-161.

Durbec P, Gennarini G, Goridis C, Rougon G (1992) A soluble form of the F3 neuronal cell adhesion molecule promotes neurite outgrowth. J Cell Biol 117:877-887.
El Majdoubi M, Poulain DA, Theodosis DT (1997) Lactation-induced plasticity in the supraoptic nucleus augments axodendritic and axosomatic gabaergic and glutamatergic synapses: an ultrastructural analysis using the disector method. Neuroscience 80:1137-1147.

Faivre-Sarrailh C, Rougon G (1997) Axonal molecules of the immunoglobulin superfamily bearing a GPI anchor: their role in controlling neurite outgrowth. Mol Cell Neurosci 9:109-115.

Faivre-Sarrailh C, Gennarini G, Goridis C, Rougon G (1992) F3/11 cell surface molecule expression in the developing mouse cerebellum is polarized at synaptic sites and within granule cells. J Neurosci 12:257-267.

Gainer H, Wray S (1994) Cellular and molecular biology of oxytocin and vasopressin. In: The physiology of reproduction, Ed 2 (Knobil E, Neill JD, eds), pp 1099-1129. New York: Raven.

Gennarini G, Cibelli G, Rougon G, Mattei M, Goridis C (1989) The mouse neuronal cell surface protein F3: a phosphatidylinositolanchored member of the immunoglobulin superfamily related to chicken contactin. J Cell Biol 109:775-788.

Gennarini G, Durbec P, Boned A, Rougon G, Goridis C (1991) Transfected F3/F11 neuronal cell surface protein mediates intercellular adhesion and promotes neurite outgrowth. Neuron 6:595-606.

Grant NJ, Leon C, Aunis D, Langley OK (1992) Cellular localization of the neural cell adhesion molecule-L1 in adult rat neuroendocrine and endocrine tissues: comparisons with NCAM. J Comp Neurol 325:548-558.

Hatton GI (1997) Function-related plasticity in the hypothalamus. Annu Rev Neurosci 20:375-397.

Itoh K, Stevens B, Schachner M, Fields RD (1995) Regulated expression of the neural cell adhesion molecule L1 by specific patterns of neural impulses. Science 270:1369-1372.

Kiss JZ, Wang C, Rougon G (1993) Nerve-dependent expression of high polysialic acid neural cell adhesion molecule in neurohypophysial astrocytes of adult rats. Neuroscience 53:213-222.

Kiss JZ, Wang C, Olive S, Rougon G, Lang J, Baetens D, Harry D, Pralong WF (1994) Activity-dependent mobilization of the adhesion molecule polysialic NCAM to the cell surface of neurons and endocrine cells. EMBO J 13:5284-5292.

Le Moine C, Bloch B (1995) D1 and D2 dopamine receptor gene expression in the rat striatum: sensitive cRNA probes demonstrate prominent segregation of D1 and D2 mRNAs in distinct neuronal populations of the dorsal and ventral striatum. J Comp Neurol 355:418-426.

Lierheimer R, Kunz B, Vogt L, Savoca R, Brodbeck U, Sonderegger P (1997) The neuronal cell-adhesion molecule axonin-1 is specifically released by an endogenous glycosylphosphatidylinositol-specific phospholipase. Eur J Biochem 243:502-510.

Moll UM, Lane BL, Robert F, Geenen V, Legros JJ (1988) The neuroendocrine thymus. Abundant occurrence of oxytocin-, vasopressinand neurophysin-like peptides in epithelial cells. Histochemistry 89:385-390.

Muller D, Wang C, Skibo G, Toni N, Cremer H, Calaora V, Rougon G, Kiss JZ (1996) PSA-NCAM is required for activity-induced synaptic plasticity. Neuron 17:413-422.

Navone F, Di Gioia G, Jahn R, Browning M, Greengard P, De Camilli P (1989) Microvesicles of the neurohypophysis are biochemically related to small synaptic vesicles of presynaptic nerve terminals. J Cell Biol 109:3425-3433.

Nothias F, Vernier P, Von Boxberg Y, Mirman S, Vincent JD (1997) Modulation of NCAM polysialylation is associated with morphofunctional modification in the hypothalamo-neurohypophysial system during lactation. Eur J Neurosci 9:1553-1565.

Olive S, Dubois C, Schachner M, Rougon G (1995a) The F3 neuronal GPI-linked molecule is localized to glycolipid-enriched membrane subdomains and interacts with L1 and fyn-kinase in cerebellum. J Neurochem 65:2307-2317.

Olive S, Rougon G, Pierre K, Theodosis DT (1995b) Expression of a glycosyl phosphatidylinositol-anchored adhesion molecule, the glycoprotein F3, in the adult rat hypothalamo-neurohypophysial system. Brain Res 689:271-280.

Peles E, Nativ M, Campbell PL, Sakurai T, Martinez R, Lev S, Clary DO, Schilling J, Barnea G, Plowman GD, Grumet M, Schlesinger J (1995) The carbonic anhydrase domain of receptor tyrosine phosphatase beta is a functional ligand for the axonal cell recognition molecule contactin. Cell 82:251-260.

Pesheva P, Probstmeier R, Skubitz APN, McCarthy JB, Furcht LT, Schachner M (1994) Tenascin-R (J1 160/180) inhibits fibronectin- 
mediated cell adhesion functional relatedness to tenascin-C. J Cell Sci 107:2323-2333.

Poulain DA, Wakerley JB (1982) Electrophysiology of hypothalamic magnocellular neurones secreting oxytocin and vasopressin. Neuroscience 7:773-808.

Roberts MM, Robinson AG, Hoffman GE, Fitzsimmons MD (1991) Vasopressin transport regulation is coupled to synthesis rate. Neuroendocrinology 53:416-422.

Sakurai T, Lustig M, Nativ M, Hemperly JJ, Schlessinger J, Peles E, Grumet M (1997) Induction of neurite outgrowth through contactin and Nr-CAM by extracellular regions of glial receptor tyrosine phosphatase beta. J. Cell Biol 136:907-918.

Shu S, Ju G, Fan L (1988) The glucose oxidase-DAB-nickel method in peroxidase histochemistry of the nervous system. Neurosci Lett 85:169-171.

Singleton PA, Salm AK (1996) Differential expression of tenascin by astrocytes associated with the supraoptic nucleus (SON) of hydrated and dehydrated adult rats. J Comp Neurol 373:186-199.

Theodosis DT (1979) Endocytosis in glial cells (pituicytes) of the rat neurohypophysis demonstrated by incorporation of horseradish peroxidase. Neuroscience 4:417-425.

Theodosis DT, Poulain DA (1993) Activity-dependent neuronal-glial and synaptic plasticity in the adult mammalian hypothalamus. Neuroscience 57:501-535.
Theodosis DT, Rougon G, Poulain DA (1991) Retention of embryonic features by an adult neuronal system capable of plasticity: polysialylated N-CAM in the hypothalamo-neurohypophysial system. Proc Natl Acad Sci USA 88:5494-5498.

Theodosis DT, Bonfanti L, Olive S, Rougon G, Poulain DA (1994) Adhesion molecules and structural plasticity of the adult hypothalamoneurohypophysial system. Psychoneuroendocrinology 19:455-462.

Theodosis DT, Pierre K, Cadoret MA, Allard M, Faissner A, Poulain DA (1997) Expression of high levels of the extracellular matrix glycoprotein, tenascin-C, in the normal adult hypothalamoneurohypophysial system. J Comp Neurol 379:386-398.

Walch-Solimena C, Takei K, Marek KL, Midyett K, Südhof TC, De Camilli P, Jahn R (1993) Synaptotagmin: a membrane constituent of neuropeptide-containing large dense-core vesicles. J Neurosci 13:3895-3903.

Yoshihara Y, Kawasaki M, Tamada A, Nagata S, Kagamiyama H, Mori K (1995) Overlapping and differential expression of BIG-2, BIG-1, TAG-1, and F3: four members of an axon-associated cell adhesion molecule subgroup of the immunoglobulin superfamily. J Neurobiol 28:51-69.

Zisch AH, D'Alessandri L, Ranscht B, Falchetto R, Winterhalter KH, Vaughan L (1992) Neuronal cell adhesion molecule contactin/F11 binds to tenascin via its immunoglobulin-like domains. J Cell Biol 119:203-213. 